\title{
Indigenous Knowledges Driving Technological Innovation
}

\author{
The Hi 'iaka Working Group
}

\section{Summary}

This policy brief explores the use and expands the conversation on the ability of geospatial technologies to represent Indigenous cultural knowledge. Indigenous peoples' use of geospatial technologies has already proven to be a critical step for protecting tribal self-determination. However, the ontological frameworks and techniques of Western geospatial technologies differ from those of Indigenous cultures, which inevitably lead to mistranslation and misrepresentation when applied to cultural knowledge. The authors advocate the creation of new technologies that are more conducive to Indigenous ontologies and epistemologies in an effort to break down the barriers to the expression and preservation of cultural heritage and cultural survival.

Introduction

The values and priorities of land use, resource management, and environmental stewardship of the dominant culture often do not mesh well with the indigenous [sic] knowledge and values of a native community.

—Eric Riggs, "Field-based Education and Indigenous Knowledge"

In February 2011 a National Science Foundation-funded workshop about Indigenous ecological knowledges and geographic information sciences (GIS) was held at the Kîlauea Military Camp on the island of Hawai'i in order to explore ontologically compatible techniques and technologies. Attendees consisted of an internationally and interdisciplinary diverse set of Indigenous academics and community scholars interested in exploring those epistemologically compatible geospatial technologies capable of representing Indigenous cultural knowledge. 
All attendees recognized that current geospatial techniques and technologies have limited potential to represent Indigenous cultural knowledge and may have detrimental effects because they deemphasize, ignore, or devalue concepts that are of central importance to Indigenous cultures, including the ubiquity of relatedness, value of nonempirical experience, need to control access to all levels of geographical knowledge, and value of ambiguity over binary thought. Attendees also acknowledged the value of ontological pluralism with regard to advancing scientific research and struggling with the limitations of working with spatial knowledge systems, which emphasize dualisms such as mind-body, natureculture, space-time, and person-environment. Lastly, attendees recognized that the relationship between Indigenous and Western spatial knowledge systems is not dichotomous. They are complementary knowledge systems differing only in their emphasis on what is considered knowledge and how it is structured.

Geospatial techniques and technologies are comprised of a collection of tools, techniques, and technologies including GIS, global positioning systems, and remote sensing for managing spatial information systems. These spatial data infrastructures (SDI) are based on a Western philosophical understanding of the world. Indigenous peoples' engagement with SDI has thus far been to adapt to the Western framework because it was constructed without regard to Indigenous spatial knowledge systems. It does not take into account the way that many Indigenous people relate to the world, nor is it similar to the spatial knowledge systems inextricably intertwined with Indigenous people's cultural principles, practices, and protocols. So although SDI can easily manage environmental concerns from a Western perspective, it does not adequately address Indigenous concerns about environment and resource management. These issues were the central focus of the workshop as attendees were tasked with determining what kinds of new information and/or understandings could be gained by developing an Indigenous GIS.

Analysis

We observe the universe through a limited prism of our senses. Acknowledging the possibility, the very likelihood that there are realities that lie beyond the realm of our senses is not a debate about belief systems, so much as an examination 
of alternative methodologies. Holding on to the belief "that science must be provable, verifiable, and repeatable" excludes any and all contradictory assumptions . . . and that IS NOT science that is politics.

\section{-Peter MacNicol as Dr. Larry Fleinhardt in Numb3rs, CBS drama}

To ensure that our conversations about the task at hand truly embodied Indigenous epistemologies, we centered ourselves in the Hawaiian process of creation. Workshop attendees began with a multisensory series of Kīpaepae, or setting of the foundation. One of the key aspects of Indigenous epistemologies is that of orienting oneself to the landscape and to each other's spirit as family. The initial Kippaepae ceremonies and exchanges are designed to potentiate our capacity as a diverse group of scholars and practitioners to arrive at a shared goal. We were immersed in a didactic curriculum that continuously attempted to anchor our relationship to place and space through wahi pana (sacred geographies), kapa (bark cloth) making, and hula (dance). We began with an intimate introduction to the Hawaiian consciousness by visiting the sacred geographies of Hilo that revealed obvious relationships between elemental phenomenon and ecological knowledge. Kapa making challenged our dexterity and patience as we were given an opportunity to "felt" our combined experiences into the fabric and framework of the "creative process." Hula as the embodiment of Hawaiian spatial knowledge engaged our minds and bodies synergistically as a ritualized celebration of a reciprocal relationship with nature.

Participation in these Hawaiian practices was designed for attendees to recall and share cultural practices from their own homelands. These experiential learning sessions became the foundation for our themed discussions. We set out to address four main research questions:

1. What are the characteristics and elements of an Indigenous GIS that is based on Indigenous epistemologies?

2. How do these characteristics differ from conventional Western-based GIS?

3. What kind of data model and structures are best suited to the characteristics of an Indigenous GIS? 
4. What standards and protocols can be developed for an Indigenous GIS?

However, we learned fairly quickly that while we prepared our metaphoric minds (Cajete, 2000) for this discussion, our disciplinary engagements with the nature-culture-technology nexus were too disparate to begin with these questions.

Findings

Indigenuity - the ability to solve pressing life issues facing humankind now by situating our solutions in Earth-bound local Indigenous deep spatial knowledges.

—Curtis Kekahbah, Kaw Nation in Wildcat 2009

We learned that before we could identify the characteristic elements of an Indigenous GIS we needed to know what we wanted to represent about our relationship to our homelands. So our discussion initially revolved around the politics of mapping and representation of place. Although geographers and cartographers have already addressed these concepts for more than a decade, anthropologists, biologists, ecologists, intellectual property lawyers, language programmers, linguists, and mathematicians have not discussed these ideas in depth.

We took a session to air concerns about historic misrepresentations due to culturally inadequate translations and about the distrust many of the elders in our homelands felt toward sharing cultural knowledge, including the ecological knowledge that could help people better prepare for sustainable livelihoods. After lively exchanges, we arrived at a point in our workshop at which we could begin addressing our four main research questions.

Throughout the workshop, our four main questions were posted on the wall and attendees were given large sticky notepads to write their ideas down and attach them to the posters. Blank poster-size sticky notepads were available for attendees to write their own questions that they wanted others to answer. Sometimes ideas arrive as a result of movement, so we encouraged attendees to express themselves through art. A walk in the forest proved to be a welcome energizer. By the end of the workshop, almost all of the questions were answered and new ones were addressed.

1. What are the characteristics and elements of an Indigenous GIS that is based on Indigenous epistemologies? 
- Connectedness and relationships;

- Ethical and respectful;

- Identity, genealogy, and demographics;

- Dynamic;

- Ability to move back and forth through time and across space;

- Reciprocity;

- Values/beliefs in nonhuman persons in the landscape; and

- Flexible/adaptable for multiple communities.

2. How do these characteristics differ from conventional Western-based GIS?

- Pluralistic not monotheistic.

3. What kind of data model and structures are best suited to the characteristics of an Indigenous GIS?

- Represent meaning and function versus thing and location; redefine landscape as function versus using maps for ownership.

- Map the function, process, use, and genealogy. How the land owns us, not how we own the land.

- Consider a flexible, customizable model, which provides the space for each community to determine the types of knowledge needed to populate it.

4. What standards and protocols can be developed for an Indigenous GIS?

- Integrate a conversation about the types of safeguards that are expected by your community into the ad hoc consultation processes associated with the development and implementation of the anticipated GIS model. A menu of options is available, which can be tailored to particular contexts.

- Be able to represent action as a "layer" (versus just a "thing").

- Respect the sacred through ritualized protocols.

- Time as coincident with space and place.

5. What would a system based on Indigenous spatial realities, practices, protocols, and presentations look like?

- From the zenith of the sky to the core of the earth. From the potential being through the long and everlasting night into the world of light. From the morning star and the breath of life through the passion of the warm southern winds, through to the dark home of the thunders into the long night of wisdom. In the center dwells the everlasting spark of spirit that animates our being. 


\section{Recommendations}

Although the workshop was not geared toward creating clear policy recommendations, it did assist those involved in envisioning a research agenda that will further our aim of representing Indigenous knowledge of particular places and landscapes in new ways that meld Western cartographic techniques with Indigenous cartographic traditions. The creation of such an Indigenous GIS would benefit both ends of the social spectrum from policy makers and scientists to community members and Indigenous practitioners. It would allow for spatial analysis and modeling to be based on Indigenous understandings of the interrelatedness of natural phenomena.

A significant step toward creating these new representational techniques is the creation of protocols for accessing and respecting Indigenous knowledges within our cross-cultural research initiative. Much work has been done throughout the past decade toward creating general research protocols (e.g., Bishop, 1996; Louis, 2007; Kliskey, Alessa, and Barr, 2009; Smith, 1999; Wilson, 2008). This research initiative will require the development of specific protocols related to methods of representing Indigenous knowledge in new and innovative ways that are also respectful and of use to the communities involved. To succeed it will be imperative for agencies, training institutions, and communities to support the training of practitioners versed in science and technology and in Indigenous knowledge and protocol.

Another significant challenge for this research is that very little work has been published at the intersection of Indigenous knowledge and sustainability science. Despite the fact that there is a great deal of interest in the sustainable practices of various Indigenous communities, this interest has not equated with research. We call on those interested in further developing sustainability science to engage in meaningful dialogue with Indigenous communities in which valuable lessons may be learned. More specifically, agencies can engage with Indigenous groups to support these research initiatives through collaborations in which communities are an equal partner and have the ability to influence the direction of the research and set the research questions. For federal agencies to support the research of the sustainability practices of Indigenous groups requires policy makers in those agencies to have interdisciplinary skills, an awareness and understanding of multiple ways 
of knowing, and a willingness to work outside of their comfort zone, which may necessitate taking risks.

\section{Conclusion}

The workshop process lit a fire within each of us to continue working toward our own individual ventures as we recognized that they are the necessary parts of creating an epistemologically compatible spatial knowledge infrastructure. During the final hours of our workshop, our interdisciplinary group of academics and community scholars committed (to varying degrees) to the formation of a family unit. The primary focus of this international unit is the nurturing of a new Indigenous GIS (IGIS) child-entity that truly embodies Indigenous epistemologies. The birth name of our IGIS child-entity is Hi'iaka. As Hi' iaka matures and transforms, this child-entity will inherit ancestral knowledge from each of the sacred spaces of our family group. At every stage of maturation, each international family member will rename Hi'iaka as we create infrastructure and protocols capable of harnessing the knowledge that we maintain from our ancestors without dilution or mass consumption. Data, in isolation, is not an adequate technological component of Indigenous spatial knowledge sharings. Ancestral knowledge is place-specific and maintained in metaphoric stasis awaiting mythic maturation of enlightened practitioners. Ola 'o Hi'iaka! Life to all!

\section{Acknowledgments}

The Hi'iaka Working Group, the workshop attendees, and co-authors are Lilian Alessa, Carlos Andrade, Phil Cash Cash, Christian P. Giardina, Matt Hamabata, Craig Hammer, Kai Henifin, Lee Joachim, Jay T. Johnson, Kekuhi Kealiikanakaoleohaililani, Deanna Kingston, Andrew Kliskey, Renee Pualani Louis, Amanda Lynch, Daryn McKenny, Chels Marshall, Mere Roberts, Taupouri Tangaro, Jyl Wheaton-Abraham, and Everett Wingert.

The authors are grateful to the National Science Foundation (Award \#1044906) for funding the workshop at Kìlauea in February 2011 and to Program Director Anna Kerttula for her support and encouragement for the workshop. The views expressed here do not necessarily reflect those of the National Science Foundation.

\section{References}

Bishop, Russell. 1996. Collaborative Research Stories = Whakawhanaungatanga. Academic monograph. Palmerston North, NZ: Dunmore Press. 
Cajete, Gregory. 2000. Native Science: Natural Laws of Interdependence. 1st ed. Santa Fe, NM: Clear Light Publishers.

Kliskey, Andrew, Alessa, Lilian, and Brad Barr. 2009. "Integrating Local and Traditional Ecological Knowledge for Marine Resilience." Pp. 145-61 in Managing for Resilience: New Directions for Marine Ecosystembased Management, eds. K. McLeod and H. Leslie. Washington, DC: Island Press Publishers.

Louis, Renee Pualani. 2007. "Can You Hear Us Now? Voices from the Margin: Using Indigenous Methodologies in Geographic Research." Geographical Research 45(2): 130-9.

Peter MacNicol as Dr. Larry Fleinhardt. 2006. Mind Games. In Numb3rs, directed by P. Markle. USA: Columbia Broadcasting System (CBS).

Riggs, Eric M. 2005. "Field-based Education and Indigenous Knowledge: Essential Components of Geoscience Education for Native American Communities." Science Education 89(2): 296-313.

Smith, Linda Tuhiwai. 1999. Decolonizing Methodologies: Research and Indigenous Peoples. London: Zed Books.

Wildcat, Daniel R. 2009. Red Alert! Saving the Planet with Indigenous Knowledge. Golden, CO: Fulcrum.

Wilson, Shawn. 2008. Research Is Ceremony: Indigenous Research Methods. Black Point, NS: Fernwood Publishing.

The name "Hi'iaka" embodies the processes of regeneration, restoration, newness, and growth through a deep sense of social-ecological protocols. The Hi'iaka Working Group intends to generate dynamic, spatial, and multiperceptual ways of viewing the world through Indigenous technologies, such as IGIS. We are a new global family of cultural practitioners, scholars, academics, nonprofits, for-profits, governmental and nongovernmental agencies, and community leaders. We have ancestral ties to the original peoples of Hawai'i, Australia, Aotearoa, Alaska, and America, and we share a passion for traditional wisdom, technology, the health of our peoples, and the health of our earth. 